\title{
X-linked spondyloepimetaphyseal dysplasia
}

INSERM

\section{Source}

INSERM. (1999). Orphanet: an online rare disease and orphan drug data base. $\underline{X-l i n k e d}$ spondyloepimetaphyseal dysplasia. ORPHA:93349

X-linked spondyloepimetaphyseal dysplasia is a rare, genetic primary bone dysplasia disorder characterized by disproportionate short stature with mesomelic short limbs, leg bowing, lumbar lordosis, brachydactyly, joint laxity and a waddling gait. Radiographs show platyspondyly with central protrusion of anterior vertebral bodies, kyphotic angulation and very short long bones with dysplastic epiphyses and flarred, irregular, cupped metaphyses. 